\title{
MANEJO TRADICIONAL DA PESCA NA ÁREA DE PROTEÇÃO AMBIENTAL DO DELTA DAS AMÉRICAS
}

\author{
Leidimar Lustosa Alves Feitosa ${ }^{1}$ \\ Maria Claudene Barros ${ }^{2}$ \\ Zafira da Silva de Almeida ${ }^{3}$
}

Resumo: Este estudo analisa a pesca em Barra Grande, município de Cajueiro da Praia-PI, identificando atributos de sustentabilidade e práticas de manejo que demonstram a sustentabilidade dos modelos de exploração com base no conhecimento tradicional dos pescadores entrevistados. Constatou-se a existência de atributos de sustentabilidade envolvendo as dimensões social, ecológica, tecnológica, econômica e de manejo da pesca e foram caracterizados oito sistemas de pesca, cujas medidas de manejo tradicional como a construção de marambaias têm contribuído para a continuidade da atividade. Assim, atributos e medidas de manejos constatados revelam aspectos que subsidiam a sustentabilidade pesqueira na comunidade e que necessitam ser contemplados nas ações de gestão da área.

Palavras-chave: Atributos de Sustentabilidade; Práticas de Manejo; Sistemas de Pesca Artesanal; Barra Grande-PI.

\footnotetext{
1 Universidade Estadual do Maranhão. E-mail: leidimarlustosa@gmail.com

2 Universidade Estadual do Maranhão. E-mail: mbdene@yahoo.com.br

3 Universidade Estadual do Maranhão: E-mail: zafiraalmeida@hotmail.com
} 


\section{Introdução}

A atividade pesqueira é uma prática composta por diversas etapas que compreende desde os processos de captura dos recursos até atividades de explotação, exploração, cultivo, conservação, processamento, transporte, comercialização e pesquisa (BRASIL, 2009). No cenário nacional, constitui um dos pilares fundamentais da socioeconomia do país, por contribuir de maneira significativa para a segurança alimentar, gerar emprego e renda (DIAS NETO, 2010). Em pequenas comunidades, encontra-se alicerçada na pesca artesanal, base de sustentação econômica, social e cultural de populações ribeirinhas e litorâneas.

Este tipo de atividade é praticado por comunidades tradicionais, povos que no Brasil são reconhecidos pelo Decreto Federal 6.040/2007 (BRASIL, 2007) como os pescadores artesanais e os indígenas. A pesca artesanal é considerada sustentável por utilizar modelos de exploração caracterizados pela singularidade e diversidade de práticas que, embasadas no conhecimento tradicional, apresentam baixo impacto (SANTOS et al., 2012).

A ligação que a etnobiologia estabelece entre o conhecimento científico e as diversas culturas, pode ser a base para incluir o conhecimento tradicional em ações de desenvolvimento sustentável (POSEY, apud PEZZUTI et al., 2010). Dessa forma, estudos que contemplam o conhecimento de pescadores geram dados relevantes para o desenvolvimento e aprimoramento de sistemas de manejo pesqueiro, sendo assim, uma forte ferramenta na formulação de políticas apropriadas de manejo pesqueiro (SILVANO; BEGOSSI, 2012).

O reconhecimento do saber dos pescadores nos sistemas de manejo tem possibilitado compreensão das relações sociais, tecnológicas, econômicas e ecológicas existentes na pesca e subsidiado a elaboração de políticas públicas voltadas para a sustentabilidade dos sistemas ecológicos e das pescarias (BASÍLIO et al., 2015). Neste sentido, Almeida e Nahum (2015) ressaltam que a continuidade das práticas pesqueiras existentes nas comunidades tradicionais necessita ser analisada de maneira integral, considerando dimensões que reflitam a sustentabilidade da atividade.

Diante do exposto e considerando que Santos et al. (2012) apontam a falta de estudos que demonstrem a sustentabilidade dos modelos de exploração da pesca artesanal em Unidades de Conservação, este estudo buscou analisar com base no conhecimento tradicional de pescadores, a situação da pesca em Barra Grande, comunidade que integra a Área de Proteção Ambiental (APA) do Delta das Américas, buscando identificar atributos de sustentabilidade e constatar a existência de manejo tradicional, a fim de que essas informações possam subsidiar a gestão da pesca na área com vistas à continuidade da atividade. 


\section{Metodologia}

O litoral piauiense, assim como toda a área do Delta das Américas, é uma região fluviomarinha, cuja elevada produtividade primária e heterogeneidade de ambientes atrai, para fins reprodutivos, espécies migratórias (GUZZI, 2012), constituindo local relevante para a biodiversidade marinha, além de refugiar espécies ameaçadas de extinção (DUTRA; PEREIRA, 2015) como o mero (Epinephelus itajara) e o camurupim (Megalops atlanticus).

Em termos geológicos, de acordo com Baptista e Horn Filho (2014), diversas feições geomorfológicas caracterizam os $66 \mathrm{~km}$ de litoral piauiense, destacando-se a ocorrência de recifes de arenito. Em Barra Grande, município litorâneo de Cajueiro da Praia, situado na região norte do estado do Piauí, sob as coordenadas $02^{\circ} 55^{\prime} 40^{\prime \prime S}$ e $41^{\circ} 24^{\prime} 40^{\prime \prime} \mathrm{W}$, os recifes de arenito caracterizam a praia desta comunidade.

Marcada pela presença de abundante biodiversidade de espécies marinhas e terrestres, a praia de Barra Grande é a maior do município, com 4 $\mathrm{km}$ de extensão. $\mathrm{O}$ clima da área é tropical com elevada pluviosidade devido à influência da massa Equatorial Atlântica (DUTRA; PEREIRA, 2015) com período chuvoso ocorrendo entre os meses de janeiro a maio e o de estiagem de junho a dezembro (FREITAS et al., 2012). O período seco é marcado por fortes ventos, sobretudo nos meses de agosto, setembro e outubro (CAVALCANTI, 2000).

$\mathrm{Na}$ pesquisa de campo, referenciaram-se dados qualitativos e quantitativos de 87 (22\%) pescadores artesanais de Barra Grande. O tamanho da amostra foi calculado conforme sugerido por Barbetta (2006), com um erro amostral de $10 \%$, tendo por base o número de pescadores associados à Colônia de Pescadores Z-6 e residentes em Barra Grande, sendo os informantes selecionados de acordo com o método Bola de Neve (BAILEY, 1994).

Os dados foram gerados a partir de quatro visitas à comunidade, com duração de quatro dias cada, no período de julho a agosto de 2017. Informações sobre os sistemas de pesca e as ações de manejo foram obtidas por meio de entrevista semiestruturada e protocolo observacional, registradas por meio de gravações de áudio, fotografias e diário de campo. A marcação geográfica dos sistemas de pesca estuarina foi realizada com o auxílio de três pescadores e de uma marisqueira durante três incursões, duas embarcadas e uma desembarcada, sendo os pontos registrados com o aplicativo GPS essentials integrado a um dispositivo móvel. As coordenadas dos sistemas costeiros foram fornecidas por três pescadores, excetuando-se o sistema de produção pesqueira curral obtida por incursão desembarcada à área de pesca durante a maré baixa.

A identificação dos atributos de sustentabilidade pesqueira teve por base a literatura disponível (HAIMOVICI, 2011; ALMEIDA; NAHUM, 2015; BASÍLIO 
et al., 2015). Os dados quantificáveis foram analisados segundo a frequência relativa de ocorrência e os qualitativos por meio da descrição de categorias identificadas no discurso dos entrevistados.

Esta pesquisa foi autorizada pelo Comitê de Ética da Plataforma Brasil, processo no 65597517.1.0000.5554 e pelo Instituto Chico Mendes de Conservação da Biodiversidade (ICMBio), protocolo no 57394-1 e com permissão prévia dos entrevistados através do Termo de Consentimento Livre e Esclarecido.

\section{Resultados e Discussão}

\section{Sustentabilidade da pesca artesanal em Barra Grande}

Indicadores de sustentabilidade que possibilitem o monitoramento da pesca, bem como subsidiem soluções favoráveis para o setor, são fundamentais para o estabelecimento de formas apropriadas de gestão pesqueira (ALMEIDA et al., 2010). Assim, foram identificados e descritos 19 atributos de sustentabilidade que caracterizam a atividade pesqueira em Barra Grande (Tabela 1).

Tabela 1: Dimensões dos atributos de sustentabilidade identificados na atividade pesqueira artesanal em Barra Grande, Cajueiro da Praia-PI em 2017.

\begin{tabular}{|c|c|c|c|}
\hline \multicolumn{4}{|c|}{ DIMENSÃO SOCIAL } \\
\hline Atributos & Descrição & Caracterização & $\begin{array}{l}\text { Referência de } \\
\text { análise }\end{array}$ \\
\hline $\begin{array}{l}\text { Benefícios } \\
\text { assistenciais }\end{array}$ & $\begin{array}{c}\text { Percentual de } \\
\text { entrevistados com } \\
\text { vantagens sociais } \\
\text { ligadas à pesca }\end{array}$ & $\begin{array}{c}85,1 \% \text { recebem ou receberam } \\
\text { seguro desemprego } \\
2,3 \% \text { receberam auxílio } \\
\text { natalidade }\end{array}$ & Muito boa $>60 \%$ \\
\hline $\begin{array}{l}\text { Origem dos } \\
\text { pescadores }\end{array}$ & $\begin{array}{l}\text { Entrevistados que } \\
\text { residem com suas } \\
\text { famílias na } \\
\text { comunidade }\end{array}$ & $\begin{array}{c}\text { Todos os entrevistados e suas } \\
\text { famílias residem na comunidade } \\
\text { há pelo menos } 6 \text { anos }\end{array}$ & $(\geq 80 \%)$ \\
\hline $\begin{array}{l}\text { Organização } \\
\text { social }\end{array}$ & $\begin{array}{c}\text { Situação da } \\
\text { organização social } \\
\text { dos entrevistados }\end{array}$ & $\begin{array}{l}85,1 \% \text { são ou foram associados } \\
\text { à Colônia de Pesca Z-6 }\end{array}$ & $\begin{array}{l}\text { Existe e possui } \\
\text { adesão comunitária }\end{array}$ \\
\hline $\begin{array}{l}\text { Qualidade da } \\
\text { moradia }\end{array}$ & $\begin{array}{l}\text { Condições de moradia } \\
\text { dos entrevistados } \\
\text { considerando a } \\
\text { situação regional }\end{array}$ & $\begin{array}{c}\text { 83,9\% possuem casa própria } \\
\text { 98,9\% com cobertura de telha } \\
82,8 \% \text { feita de alvenaria } \\
55,2 \% \text { piso de cimento } \\
44,8 \% \text { piso de cerâmica } \\
86,2 \% \text { coletada de lixo } \\
\text { 96,5\% possuem fossa séptica } \\
100 \% \text { possuem energia elétrica }\end{array}$ & $\begin{array}{c}\text { Ótima } \\
\text { (Alvenaria, luz e } \\
\text { condições sanitárias } \\
\geq 80 \% \text { ) }\end{array}$ \\
\hline
\end{tabular}

Continua... 
...continuação.

\begin{tabular}{|c|c|c|c|}
\hline \multicolumn{4}{|c|}{ DIMENSÃO ECOLÓGICA } \\
\hline $\begin{array}{l}\text { Grau de } \\
\text { vulnerabilidade }\end{array}$ & $\begin{array}{c}\text { Nível de } \\
\text { vulnerabilidade do } \\
\text { ecossistema } \\
\text { considerando o local } \\
\text { de atuação dos } \\
\text { entrevistados } \\
\end{array}$ & $\begin{array}{c}5,7 \% \text { atuam no mangue } \\
24,2 \% \text { atuam na zona costeira } \\
70,1 \% \text { atuam no estuário ou } \\
\text { praia }\end{array}$ & $\begin{array}{c}\text { Alto } \\
\text { (Mangue e recife) } \\
\text { Médio Alto (Estuário) } \\
\text { Médio Baixo (Praia) } \\
\text { Baixo } \\
\text { (Plataforma) }\end{array}$ \\
\hline $\begin{array}{l}\text { Grau de } \\
\text { degradação }\end{array}$ & $\begin{array}{l}\text { Grau de degradação } \\
\text { do ecossistema } \\
\text { relacionado com o } \\
\text { impacto da arte ou de } \\
\text { outros fatores } \\
\text { antrópicos }\end{array}$ & $\begin{array}{l}\text { Os ecossistemas encontram-se } \\
\text { bem conservados, mas já } \\
\text { existem problemas como } \\
\text { assoreamento do estuário e } \\
\text { poluição do mangue devido a } \\
\text { fatores antrópicos }\end{array}$ & $\begin{array}{c}\text { Ótimo } \\
\text { (Conservado) }\end{array}$ \\
\hline $\begin{array}{l}\text { Número de } \\
\text { espécies }\end{array}$ & $\begin{array}{l}\text { Quantidade de espé- } \\
\text { cies-alvo capturadas } \\
\text { pelas artes de pesca }\end{array}$ & $\begin{array}{l}\text { As artes utilizadas podem } \\
\text { capturar espécies diferentes, } \\
\text { conforme ambiente explorado }\end{array}$ & $\begin{array}{c}\text { Ótimo } \\
\text { (Multiespecíficas } \\
>10)\end{array}$ \\
\hline $\begin{array}{l}\text { Nível de } \\
\text { descarte }\end{array}$ & $\begin{array}{l}\text { Nível de descarte das } \\
\text { pescarias }\end{array}$ & $\begin{array}{c}\text { As pescarias cujos produtos são } \\
\text { peixes e o caranguejo o nível de } \\
\text { descarte é nulo. Sendo relatado } \\
\text { e observado o descarte das } \\
\text { valvas dos moluscos }\end{array}$ & $\begin{array}{l}\text { Bom } \\
\text { (Baixo) } \\
\text { Ótimo } \\
\text { (Nulo) }\end{array}$ \\
\hline $\begin{array}{l}\text { Estado de } \\
\text { explotação }\end{array}$ & $\begin{array}{l}\text { Nível de exploração } \\
\text { da atividade segundo } \\
\text { os entrevistados } \\
\text { DIME }\end{array}$ & $\begin{array}{l}50 \% \text { afirmam que o número de } \\
\text { pescadores tem diminuído nos } \\
\text { últimos } 10 \text { anos. Relatam tanto a } \\
\text { diminuição como o } \\
\text { reaparecimento de pescados } \\
\text { SÃO TECNOLÓGICA }\end{array}$ & $\begin{array}{c}\text { Médio } \\
\text { (Explorado } \\
\text { moderadamente) }\end{array}$ \\
\hline Seletividade & $\begin{array}{c}\text { Grau de seletividade } \\
\text { da arte de pesca } \\
\text { utilizada }\end{array}$ & $\begin{array}{c}\text { Utilizam artes como a caçoeira } \\
\text { com abertura de malhas } \\
\text { variando de } 5 \text { a } 14 \mathrm{~cm} \text {, que } \\
\text { permite a captura de pescados } \\
\text { maiores e variados; linha de mão } \\
\text { e a estratégia manual que são } \\
\text { monoespecíficas }\end{array}$ & $\begin{array}{c}\text { Média } \\
\text { (Captura até } 10 \text { spp. } \\
\text { alvo) } \\
\text { Alta } \\
\text { (Monoespecífica) }\end{array}$ \\
\hline $\begin{array}{l}\text { Tecnologia de } \\
\text { processamento }\end{array}$ & $\begin{array}{c}\text { Utilização de } \\
\text { tecnologia de } \\
\text { conservação e } \\
\text { processamento do } \\
\text { pescado antes da } \\
\text { primeira } \\
\text { comercialização }\end{array}$ & $\begin{array}{c}\text { Empregam tecnologia de } \\
\text { processamento por meio do } \\
\text { congelamento do pescado, } \\
\text { sendo relatada a evisceração de } \\
\text { peixes por uma minoria } \\
\text { A salga é feita em pescados } \\
\text { como espada e sardinha pelos } \\
\text { pescadores de curral } \\
\text { Os catadores de caranguejo } \\
\text { vendem in natura }\end{array}$ & $\begin{array}{c}\text { Regular } \\
\text { (Nenhuma) } \\
\text { Bom } \\
\text { (Salga, gelo, } \\
\text { eviscera, descabeça) } \\
\text { Ótimo } \\
\text { (Descasca, filé, } \\
\text { congelamento) }\end{array}$ \\
\hline $\begin{array}{l}\text { Evolução do } \\
\text { poder de pesca }\end{array}$ & $\begin{array}{c}\text { Situação do poder de } \\
\text { pesca nos últimos } 5 \\
\text { anos com o } \\
\text { incremento de barcos } \\
\text { e artes } \\
\end{array}$ & $\begin{array}{l}\text { Relatam que o poder de pesca } \\
\text { tem se apresentado estável sem } \\
\text { mudanças significativas nas } \\
\text { embarcações e artes utilizadas }\end{array}$ & $\begin{array}{l}\text { Ótimo } \\
\text { (Estável) }\end{array}$ \\
\hline $\begin{array}{l}\text { Petrecho no } \\
\text { ecossistema }\end{array}$ & $\begin{array}{l}\text { Efeito do petrecho } \\
\text { sobre o ecossistema }\end{array}$ & $\begin{array}{c}\text { As artes utilizadas pelos } \\
\text { entrevistados não destroem o } \\
\text { ambiente }\end{array}$ & $\begin{array}{c}\text { Ótimo } \\
\text { (Não destrutivo) }\end{array}$ \\
\hline
\end{tabular}

Revbea, São Paulo, V. 14, № 4: 305-322, 2019. 
...continuação.

\begin{tabular}{|c|c|c|c|}
\hline \multicolumn{4}{|c|}{ DIMENSÃO ECONÔMICA } \\
\hline Renda média & $\begin{array}{l}\text { Renda média com a } \\
\text { pesca }\end{array}$ & $\begin{array}{c}\text { A renda média dos entrevistados } \\
\text { é de } R \$ 571,5\end{array}$ & $\begin{array}{c}\text { Boa } \\
(\mathrm{R} \$ 401-600)\end{array}$ \\
\hline $\begin{array}{l}\text { Dependência } \\
\text { do } \\
\text { atravessador }\end{array}$ & $\begin{array}{l}\text { Grau de dependência } \\
\text { que os pescadores } \\
\text { têm do atravessador } \\
\text { dentro do sistema }\end{array}$ & $\begin{array}{c}\text { Os pescadores vendem o } \\
\text { pescado diretamente ao } \\
\text { consumidor na praia, em suas } \\
\text { residências ou para comerciante } \\
\text { local }\end{array}$ & $\begin{array}{l}\text { Ótimo } \\
\text { (Nenhum) }\end{array}$ \\
\hline \multicolumn{4}{|c|}{ DIMENSÃO MANEJO } \\
\hline $\begin{array}{l}\text { Medidas } \\
\text { tradicionais }\end{array}$ & $\begin{array}{l}\text { Existência de medidas } \\
\text { tradicionais que } \\
\text { regulamentem o } \\
\text { sistema pesqueiro }\end{array}$ & $\begin{array}{c}\text { Existem medidas de manejo } \\
\text { tradicional de acordo com o } \\
\text { ambiente de pesca e os recursos } \\
\text { capturados }\end{array}$ & $\begin{array}{l}\text { Ótimo } \\
\text { (Muitas) }\end{array}$ \\
\hline $\begin{array}{c}\text { Medidas } \\
\text { governamentais }\end{array}$ & $\begin{array}{l}\text { Existência de medidas } \\
\text { governamentais que } \\
\text { regulamentem o } \\
\text { sistema }\end{array}$ & $\begin{array}{l}\text { Existem medidas institucionais } \\
\text { como período de defeso (IN no } \\
40 / 2005 \text { ) e fiscalização das } \\
\text { capturas do caranguejo-uçá no } \\
\text { período de reprodução (IN no } \\
6 / 2017 \text { ) } \\
\\
\text { 6. }\end{array}$ & $\begin{array}{c}\text { Bom } \\
\text { (Algumas) }\end{array}$ \\
\hline $\begin{array}{l}\text { Unidade de } \\
\text { Conservação }\end{array}$ & $\begin{array}{l}\text { Existência de Unidade } \\
\text { de Conservação }\end{array}$ & $\begin{array}{l}\text { Criação da APA do Delta das } \\
\text { Américas em } 1996\end{array}$ & $\begin{array}{c}\text { Bom } \\
\text { (Estabelecida) }\end{array}$ \\
\hline Fiscalização & $\begin{array}{c}\text { Situação de } \\
\text { fiscalização da } \\
\text { atividade na área }\end{array}$ & $\begin{array}{c}\text { O ICMBio é o órgão } \\
\text { responsável pela fiscalização } \\
\text { A Colônia de Pesca Z-6 é o } \\
\text { órgão fiscal da comunidade e os } \\
\text { próprios pescadores }\end{array}$ & $\begin{array}{c}\text { Regular } \\
\text { (Existe, mas não é } \\
\text { eficiente) }\end{array}$ \\
\hline
\end{tabular}

Fonte: Elaborado pelos autores a partir de Almeida e Nahum (2015).

A necessidade de identificar atributos de sustentabilidade na atividade pesqueira deve-se à relevância da pesca tanto para a segurança alimentar como pelo papel que desempenha na economia mundial, gerando emprego e renda para trabalhadores que dependem do setor. Estudos que objetivaram avaliar a sustentabilidade da pesca têm demonstrado a complexidade desse conceito, entretanto, pode ser entendido como a continuidade dos sistemas de pesca no tempo atual e no futuro (HAIMOVICl et al., 2014). Deste modo, conceber o processo de sustentabilidade pesqueira como continuidade da atividade depende de ações desenvolvidas no sentido de mantê-la viável em seus aspectos sociais, econômicos, tecnológicos e ecológicos.

Estudos têm analisado a sustentabilidade da pesca artesanal a partir de um conjunto de atributos agrupados em áreas temáticas que possibilitam avaliação multidimensional (HAIMOVICI, 2011; ALMEIDA; NAHUM, 2015; BASÍLIO et al., 2015). Assim, a identificação dos atributos de sustentabilidade pesqueira em Barra Grande integrou cinco dimensões que refletem o grau de "saúde" da atividade, a saber: dimensão social, ecológica, tecnológica, econômica e de manejo. 
Dos atributos identificados, na dimensão social, a organização de classe e as vantagens sociais advindas com a afiliação à colônia de pesca têm possibilitado melhorias na condição de vida dos entrevistados, fortalecendo a identidade com a comunidade e refletindo positivamente nos atributos da dimensão ecológica. Segundo Pereira e Diegues (2010), a utilização dos recursos naturais existentes nos locais de ocupação e fixação de populações tradicionais permite que desenvolvam profunda ligação com os territórios habitados. Assim, as relações com o ambiente e os saberes compartilhados e ressignificados sobre os ecossistemas e seus recursos os tornam importantes agentes de proteção ambiental.

Os atributos da dimensão ecológica identificados validam a estreita relação que os entrevistados possuem com os ambientes de pesca e os recursos explorados, posto que atuam principalmente em ambientes de baixa vulnerabilidade e pouco degradados. Já no tocante ao nível de aproveitamento dos pescados capturados, destaca-se que as marisqueiras necessitam ser orientadas a beneficiar as valvas dos moluscos e, dessa forma, evitar o desperdício e gerar renda.

A relação de dependência que possuem com os ambientes de pesca permite que percebam alterações e apontem causas para os problemas que afetam a continuidade da atividade (SANTOS et al., 2017), pois o modo de vida de comunidades tradicionais está diretamente ligado à integridade desses ecossistemas, uma vez que ao preservarem o ambiente garantem a sua própria unidade cultural (GONÇALVES et al., 2018).

Assim, mesmo sendo conhecida a situação de sobrepesca em que se encontram muitos pescados de interesse comercial no Brasil e no Mundo (DIAS NETO, 2010), os entrevistados afirmam que a maioria dos pescados existentes na comunidade continua abundante, apesar de relatos sobre diminuição na captura de recursos como a tainha (Mugil curema) e o coró (Genyatremus luteus) ao mesmo tempo em que apontam o aumento nas capturas de pescados como a garajuba (Carangoides bartholomaei) e o robalo (Centropomus spp.).

$\mathrm{Na}$ dimensão tecnológica, quatro atributos puderam ser constatados sendo o caráter seletivo das artes empregadas e o baixo impacto sobre 0 ambiente e seus recursos, fatores fundamentais para a sustentabilidade, bem como o caráter relativamente estável das artes e embarcações utilizadas nos últimos cinco anos, situação favorável à sustentabilidade por regular o poder de pesca da comunidade. De acordo com Marrul Filho (2003), o saber fazer do pescador baseado no conhecimento da dinâmica dos ambientes e das espécies exploradas, assim como das formas de localização e captura dos pescados, associados ao baixo impacto das tecnologias utilizadas contribuem para a sustentabilidade pesqueira.

Outro atributo dentro da dimensão tecnológica refere-se à tecnologia de processamento do pescado, cuja principal forma utilizada na comunidade é o congelamento. Essa forma de processamento contribui para diminuir a 
pressão sobre os estoques, posto que o pescador não realiza outra pescaria enquanto possui quantidade suficiente armazenada para a venda e o consumo. Entretanto, muitos entrevistados necessitam de incentivo financeiro para investir em equipamento adequado para armazenar e congelar sua produção.

No tocante à dimensão econômica, foram identificados dois atributos: a renda obtida com a pesca e a relação com o atravessador. Sobre a renda, 0 valor médio obtido mesmo estando situado numa faixa analisada como boa, é inferior ao valor do salário mínimo vigente em 2017, situação que limita a melhoria das condições de vida dos pescadores.

A comercialização do pescado é realizada pelos próprios pescadores na praia, no momento do desembarque ou em suas residências, não existindo a figura do atravessador, situação considerada favorável para a atividade por oportunizar maior renda com a produção. Todavia, colocam que poderiam produzir mais se existisse o atravessador, pois facilitaria a distribuição da produção. Nesse aspecto, constatou-se como a figura do atravessador está presente no imaginário dos entrevistados, que percebem sua ausência como um fator limitante da produção. Contudo, a não dependência do atravessador configura um importante atributo para a sustentabilidade pesqueira (ALMEIDA; NAHUM, 2015), não somente pelo fator econômico, mas por contribuir para uma exploração moderada dos sistemas de pesca.

Uma alternativa para viabilizar a comercialização do pescado seria a organização dos pescadores para a formação de uma cooperativa que oportunizasse o armazenamento, beneficiamento e venda do pescado ou a reabertura da fábrica de gelo da comunidade, que assegurava ao pescador não apenas o fornecimento de gelo, mas a compra do pescado.

$\mathrm{Na}$ dimensão manejo, foi possível identificar quatro atributos, ressaltando-se a existência de medidas tradicionais dos recursos explorados. Conforme Stori et al. (2012), não se faz necessário análise quantitativa de práticas de manejo, posto que, em termos socioecológicos, sua ocorrência já é significativa para o processo de resiliência e sustentabilidade por auxiliar na estabilidade dos ecossistemas e em seus processos ecológicos.

Os demais atributos de manejo referem-se às medidas governamentais, que visam assegurar a proteção ambiental e a conservação da biodiversidade na área, mas que na prática não são suficientes para garantir a sustentabilidade no uso dos recursos pesqueiros (MARRUL FILHO, 2003). Assim, ressalta-se que a efetiva integração dos pescadores e da comunidade em si, por meio de ações de Educação Ambiental e de participação na tomada de decisão sobre o uso dos recursos pesqueiros, possibilitaria maior adesão comunitária na implementação da regulamentação pesqueira, bem como agregaria conhecimento e garantiria integridade social ao processo. 


\section{Manejo tradicional da pesca}

Sistemas pesqueiros são formas de pescarias com características similares como meio aquático e relações de trabalho, além de representarem um modo complexo e integrado de dinâmicas sociais, ecológicas, econômicas e tecnológicas (HAIMOVICl et al., 2014). Dessa forma, a complexidade dos sistemas pesqueiros artesanais está relacionada aos diferentes tipos de extrativismo, tecnologias, práticas e ambientes explorados. Assim, foram identificados na área oito sistemas de pesca, três sistemas costeiros e cinco estuarinos (Figuras 1 e 2). Entretanto, ressalta-se a existência de outros sistemas, porém de menor importância econômica para a comunidade.

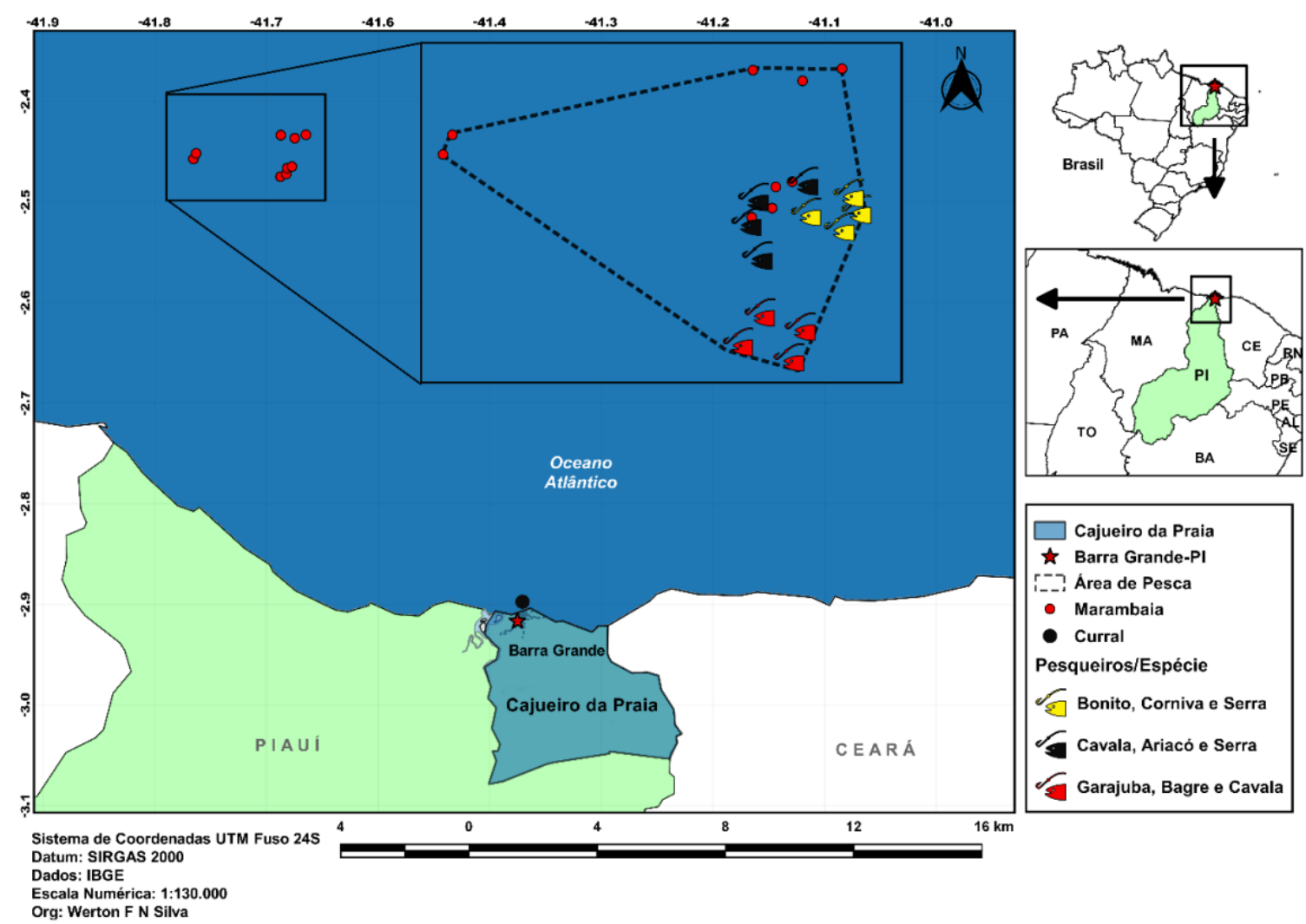

Figura 1: Localização dos Sistemas de Pesca Artesanal identificados em Barra Grande, Cajueiro da Praia-PI em 2017 - Sistemas da Zona Costeira.

Fonte: Dados resultantes da pesquisa (2017). 


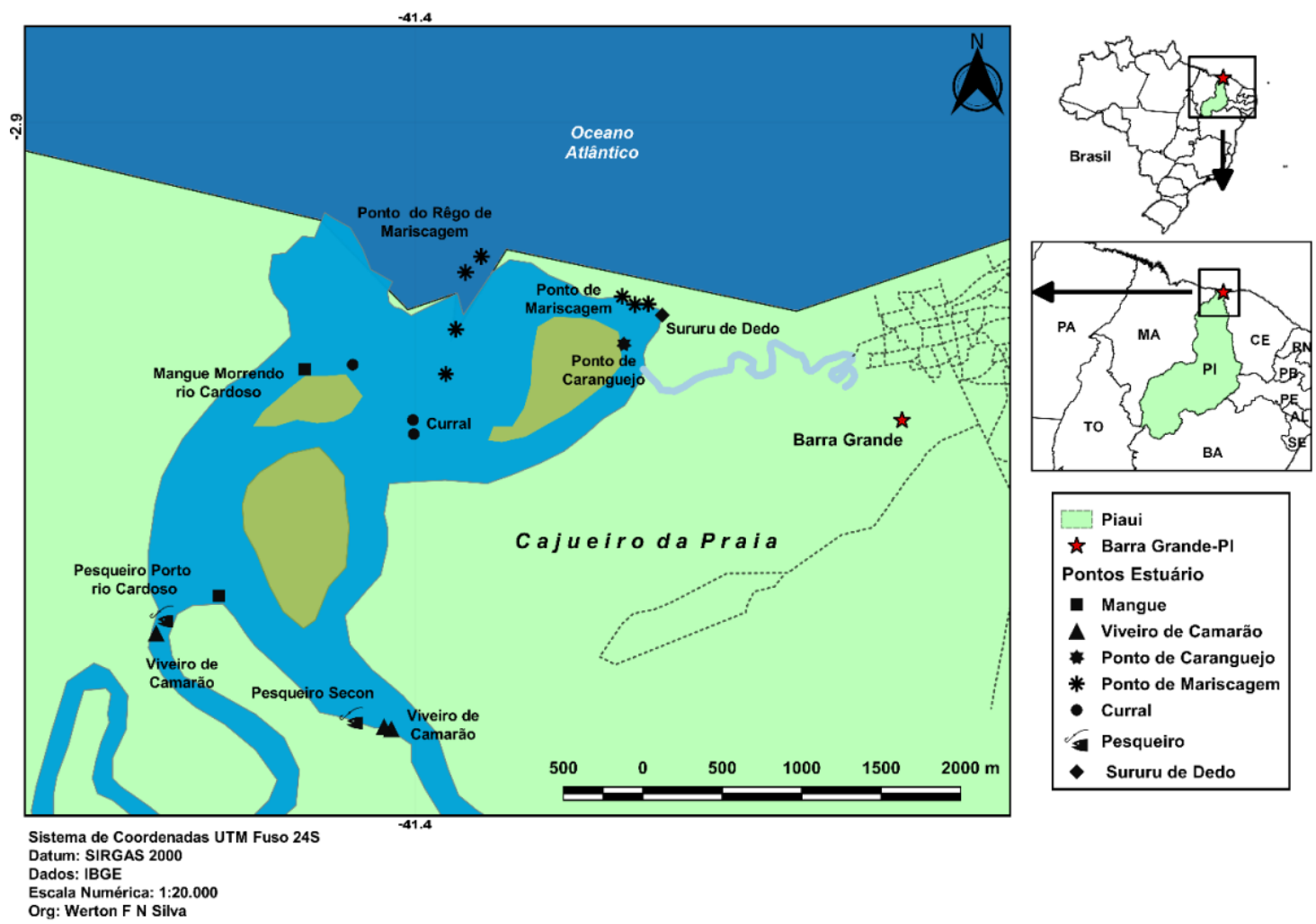

Figura 2: Localização dos Sistemas de Pesca Artesanal identificados em Barra Grande, Cajueiro da Praia-PI em 2017 - Sistemas da Região Estuarina.

Fonte: Dados resultantes da pesquisa (2017).

Para melhor compreensão da dinâmica da atividade pesqueira, particularidades dos diferentes Sistemas de Pesca devem ser consideradas, bem como as medidas de manejo inerentes a cada sistema, entendendo-se por manejo tradicional, neste estudo, práticas que contribuam para a continuidade da pesca por favorecerem a conservação dos recursos explorados e a manutenção do modo de vida dos pescadores. Dessa forma, foram caracterizados os sistemas de pesca identificados (Tabela 2).

Tabela 2: Caracterização dos Sistemas de Pesca Artesanal identificados em Barra Grande, Cajueiro da Praia-PI em 2017.

\section{SISTEMA PESQUEIRO MARAMBAIA}

\begin{tabular}{|c|c|c|c|c|}
\hline Ambiente & Frota & Arte & Principal recurso & Manejo tradicional \\
\hline Costa & $\begin{array}{l}\text { Embarcação de } \\
\text { até } 9 \mathrm{~m} \\
\text { Motorizada/vela }\end{array}$ & $\begin{array}{l}\text { Linha de } \\
\text { mão }\end{array}$ & $\begin{array}{c}\text { Ariacó } \\
\text { (Lutjanus synagris) } \\
\text { Cavala } \\
\text { (Scomberomorus } \\
\text { cavalla) }\end{array}$ & $\begin{array}{c}\text { Ambiente artificial } \\
\text { Captura sazonal } \\
\text { Espécies variadas } \\
\text { Arte seletiva } \\
\text { Devolvem os juvenis } \\
\text { Alternam as áreas }\end{array}$ \\
\hline
\end{tabular}


..continuação.

SISTEMA PESQUEIRO COSTA

\begin{tabular}{|c|c|c|c|c|}
\hline \multicolumn{5}{|c|}{ SISTEMA PESQUEIRO COSTA } \\
\hline Costa & $\begin{array}{l}\text { Embarcação de } \\
\text { até } 9 \mathrm{~m} \\
\text { Motorizada/vela }\end{array}$ & $\begin{array}{l}\text { Caçoeira } \\
\text { Espinhel } \\
\text { Tarrafa }\end{array}$ & $\begin{array}{c}\text { Bagre } \\
\text { (Sciades proops) } \\
\text { Bonito } \\
\text { (Euthynnus alletteratus) } \\
\text { Serra } \\
\text { (Scomberomorus } \\
\text { brasiliensis) }\end{array}$ & $\begin{array}{c}\text { Captura sazonal } \\
\text { Espécies variadas } \\
\text { Devolvem os juvenis } \\
\text { Alternam as áreas } \\
\text { Respeitam a } \\
\text { legislação }\end{array}$ \\
\hline \multicolumn{5}{|c|}{ SISTEMA PESQUEIRO CURRAL CORAÇÃO } \\
\hline Praia & $\begin{array}{l}\text { Embarcação de } \\
\text { até } 6 \mathrm{~m} / \text { remo }\end{array}$ & Curral & $\begin{array}{c}\text { Espada } \\
\text { (Trichiurus lepturus) } \\
\text { Xaréu } \\
\text { (Caranx hippos) }\end{array}$ & $\begin{array}{l}\text { Espécies variadas } \\
\text { Arte não predatória } \\
\text { Devolvem os juvenis }\end{array}$ \\
\hline \multicolumn{5}{|c|}{ SISTEMA PESQUEIRO ESTUÁRIO } \\
\hline Estuário & $\begin{array}{c}\text { Embarcação de } \\
\text { até } 6 \mathrm{~m} \\
\text { Motorizada/remo }\end{array}$ & $\begin{array}{l}\text { Linha de } \\
\text { mão } \\
\text { Caçoeira } \\
\text { Tarrafa }\end{array}$ & $\begin{array}{c}\text { Tainha } \\
\text { (Mugil curema) } \\
\text { Coró } \\
\text { (Genyatremus luteus) } \\
\text { Pescada } \\
\text { (Cynoscion spp.) }\end{array}$ & $\begin{array}{l}\text { Respeitam o defeso } \\
\text { Alternam as áreas } \\
\text { Direcionam as } \\
\text { pescarias para os } \\
\text { recursos mais } \\
\text { abundantes } \\
\text { Arte não predatória } \\
\text { Devolvem os juvenis }\end{array}$ \\
\hline \multicolumn{5}{|c|}{ SISTEMA PESQUEIRO BOCA DA BARRA } \\
\hline Estuário & $\begin{array}{l}\text { Embarcação de } \\
\text { até } 4 \mathrm{~m} / \text { remo }\end{array}$ & Curral & $\begin{array}{c}\text { Espada } \\
\text { (Trichiurus lepturus) } \\
\text { Sardinha } \\
\text { (Opisthonem oglinum) } \\
\text { Xaréu } \\
\text { (Caranx hippos) }\end{array}$ & $\begin{array}{l}\text { Espécies variadas } \\
\text { Arte não predatória } \\
\text { Respeitam o defeso } \\
\text { Devolvem os juvenis }\end{array}$ \\
\hline \multicolumn{5}{|c|}{ SISTEMA PESQUEIRO CARANGUEJO } \\
\hline Mangue & Sem embarcação & Manual & $\begin{array}{c}\text { Caranguejo } \\
\text { (Ucides cordatus) }\end{array}$ & $\begin{array}{c}\text { Não capturam as } \\
\text { fêmeas } \\
\text { Respeitam o } \\
\text { período de ecdise } \\
\text { Alternam as áreas }\end{array}$ \\
\hline \multicolumn{5}{|c|}{ SISTEMA PESQUEIRO MARISCO } \\
\hline Estuário & $\begin{array}{c}\text { Sem ou com } \\
\text { embarcação de } \\
\text { até } 6 \mathrm{~m} \\
\text { motorizada/ remo }\end{array}$ & Manual & $\begin{array}{c}\text { Marisco } \\
\text { (Anomalocardia } \\
\text { brasiliana) }\end{array}$ & $\begin{array}{c}\text { Não catam os } \\
\text { pequenos } \\
\text { Diminuem as } \\
\text { capturas no período } \\
\text { chuvoso }\end{array}$ \\
\hline \multicolumn{5}{|c|}{ SISTEMA PESQUEIRO SURURU } \\
\hline Mangue & $\begin{array}{c}\text { Sem ou com } \\
\text { embarcação de } \\
\text { até } 6 \mathrm{~m} \\
\text { motorizada/ remo }\end{array}$ & Manual & $\begin{array}{c}\text { Sururu } \\
\text { (Mytella guyanensis) }\end{array}$ & $\begin{array}{c}\text { Não catam os } \\
\text { pequenos } \\
\text { Diminuem a } \\
\text { produção no período } \\
\text { chuvoso }\end{array}$ \\
\hline
\end{tabular}

Fonte: Dados resultantes da pesquisa (2017). 
Nos sistemas de pesca da região estuarina, observou-se que as capturas estão condicionadas ao regime das marés e nos sistemas da zona costeira, pela sazonalidade. Assim, no período chuvoso, as pescarias ocorrem em pesqueiros naturais (pontos de pesca) geralmente marcados por GPS e no período seco em pesqueiros artificiais, as marambaias (Figura 3).

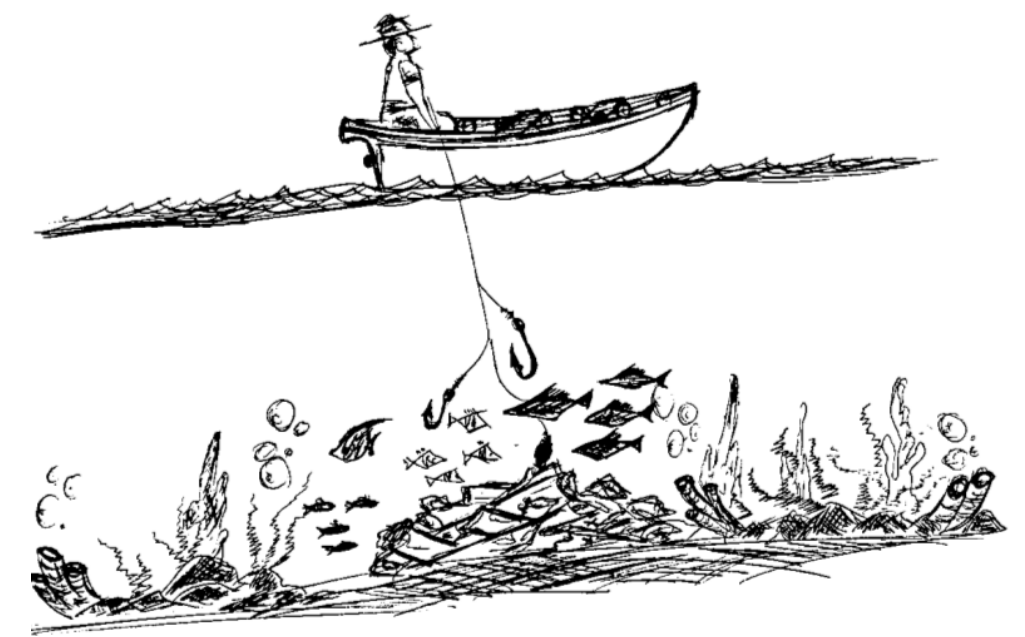

Figura 3: Desenho esquemático de uma marambaia, pesqueiro artificial situado na zona costeira de Barra Grande, Cajueiro da Praia-PI em 2017.

Fonte: Davilson Soares, morador de Barra Grande (2017).

As marambaias são ambientes de pesca construídos pelos próprios pescadores a partir de troncos de madeira amarrados com fios de nylon 250 $\mathrm{mm}$ levados anualmente nas canoas para determinadas regiões da zona costeira. Há relatos do uso de outros materiais na construção dessas estruturas como móveis velhos e eletrodomésticos, ressaltam ainda que esses objetos podem alterar as características dos ambientes de pesca, fator que tem restringido sua utilização.

Esses ambientes possuem área aproximada de $60 \mathrm{~m}^{2}$, com distância variando entre 3 a 12 milhas da costa e profundidade de até 12 braças. Constituem, segundo os entrevistados, verdadeiros berçários, além de agregarem complexa cadeia trófica, pois aos troncos se fixam algas que servem de alimento para pescados menores como as sardinhas, cuja aglomeração atrai outros pescados. A fala dos pescadores retrata a dinâmica desses pesqueiros:

O que se junta peixe, chama-se marambaia, é feita em alto mar ... nela tem a comidinha do peixe pequeno e do peixe grande, tem tudo...junta todo tipo de peixe, os grandes vêm atraídos pelos pequenos (Pescador, 51 anos).

A gente pesca de linha nela porque se pescar de rede rasga nos troncos e tem que pescar em cima dela, porque é nela que o peixe mora (Pescador, 69 anos). 
É um berçário de peixe, nela o peixe vai e vem, ele não fica preso como no manzuá e no curral. Ele fica ali até quando quiser (Pescador, 53 anos).

Apesar do esforço dos pescadores na reconstrução anual das marambaias, prática que se repete há décadas na comunidade, é este tipo de pescaria que abastece a comunidade de peixe nos meses em que a intensidade dos ventos impossibilita a maioria dos pescadores de praticar a pesca costeira devido à baixa autonomia das canoas de pequeno porte (até $6 \mathrm{~m}$ ). Assim, os pescadores que possuem embarcações maiores (entre 7 e 9 $\mathrm{m}$ ) enfrentam as condições adversas do período seco para capturar o pescado, situação que encarece a produção, mas diminui a pressão sobre os estoques. Esse tipo de pescaria tem duração de aproximadamente cinco meses, iniciando geralmente em maio.

As marambaias constituem importante forma de manejo tradicional dos recursos pesqueiros, por serem locais propícios para a alimentação e reprodução de muitos pescados que abastecem a comunidade, aumentando, então, a produtividade da área. Conceição e Nascimento (2009) relatam que a tradição de lançar ao mar galhos de árvores amarrados estimula a agregação de cardumes por oferecer refúgio e alimentação aos peixes.

Assim, a construção desses ambientes de pesca é embasada no saber prático dos pescadores que observaram a agregação de organismos em materiais lançados no fundo do mar, tornando essas áreas mais produtivas, conforme ressaltado por Padilha e Henkes (2012), bem como das áreas de pesca onde ocorre maior concentração de pescados, como recifes e costões rochosos, como os apontados no estudo de Silvano e Begossi (2012).

A prática de construção de marambaias, pesqueiros ou caiçaras denominadas na literatura científica de recifes artificiais é bastante antiga, com registros no Brasil desde o século XVII (PADILHA; HENKES, 2012), sendo atualmente considerada importante ferramenta de manejo e conservação de recursos pesqueiros.

A implementação de programas de construção de recifes artificias tem sido efetivada em diversos estados brasileiros como Ceará, Rio Grande do Norte, Pernambuco, Sergipe, Espírito Santo, Rio de Janeiro, São Paulo e Paraná utilizando materiais como pneus e cascos de embarcações (PADILHA; HENKES, 2012), sendo o uso desses materiais mais comum em comunidades populosas e próximas aos centros urbanos (CONCEIÇÃO; NASCIMENTO, 2009).

Recifes artificiais aumentam a produção pesqueira, possibilitam mergulho recreativo e protegem as áreas de pesca contra o arrasto de fundo (FAGUNDES NETTO; ZALMON, 2012), fatores que têm estimulado o uso desses ambientes como estratégia de manejo pesqueiro. Entretanto, ressaltam a necessidade de que essas áreas sejam geridas corretamente para que não 
se tornem estruturas poluidoras e degradem ainda mais o meio ambiente, devido à utilização de materiais diversos.

No Sistema Pesqueiro Costa, a pesca é realizada com maior frequência durante o período chuvoso, onde exploram diferentes recursos de acordo com a arte de pesca utilizada, sendo relatada alternância das áreas de pesca sempre que percebem a diminuição nas capturas dos recursos alvo, estratégia que tem possibilitado a renovação dos estoques. Afirmam ainda, que devolvem os pescados capturados também no estágio juvenil; muitos realizam durante a pescaria a evisceração do pescado que será utilizado para alimentar outros recursos; recolhem apetrechos como o manzuá que aprisiona o pescado; não utilizam artes consideradas prejudiciais na comunidade e evitam capturar recursos ameaçados de extinção como o mero (Epinephelus itajara), apesar de abundante na região, segundo os entrevistados.

No Sistema Curral Coração, os recursos capturados são variados, a arte não prejudica o ambiente costeiro nem as espécies exploradas, sendo devolvidos ao meio os pescados capturados no estado juvenil, estratégia bem comum entre os entrevistados.

No Sistema Pesqueiro Estuário, os pescadores capturam o suficiente para se manterem durante o período de reprodução das espécies, devolvem os juvenis e realizam alternância entre as áreas de pesca, práticas que têm contribuído para sustentabilidade da atividade.

No Sistema Curral Boca da Barra, os currais são desativados no período de defeso, sendo sua maior produção obtida no período seco, destacando-se como medida de manejo a devolução ao meio dos pescados capturados no estado juvenil, estratégia que tem favorecido o crescimento e posterior reprodução das espécies.

No Sistema Caranguejo, os entrevistados reconhecem importantes características bioecológicas do caranguejo-uçá (Ucides cordatus) que os permite diferenciar machos e fêmeas, o período de ecdise e as formas predatórias de captura. Assim, não capturam fêmeas e juvenis, e durante o período da ecdise, utilizam somente o braceamento como estratégia de captura dos machos. Essas ações são essenciais para a manutenção da espécie na área.

No Sistema Marisco e Sururu, os entrevistados afirmam coletar apenas os espécimes maiores, pois têm consciência de que os menores ainda irão crescer, demonstrando, assim, uma importante atitude de cunho ecológico para a sustentabilidade desses sistemas. Foi relatada, ainda, a mudança de atividade no período chuvoso tanto pela dificuldade de acesso nas áreas de captura, quanto pela diminuição do recurso. Nesse período, as capturas são direcionadas para outros recursos localizados na praia como a muelinha (Neritina virginea) e o búzio (Chione cancellata).

No geral, os Sistemas de Pesca identificados em Barra Grande caracterizam-se pela existência de práticas comuns de manejo como utilização de petrechos de pesca variados, seletivos e com pequeno poder de captura, 
cuja ação não tem gerado grandes impactos sobre o ambiente e os recursos; exploram diferentes espécies; as capturas são direcionadas para recursos no estágio adulto; diversificam as áreas de pesca; diminuem a atividade quando têm pescado suficiente em casa para consumo e venda ou quando os recursos tornam-se escassos e respeitam a legislação pesqueira vigente.

Ressalta-se, ainda, que a semelhança entre as práticas de manejo identificadas entre os Sistemas de Pesca sugere que regras sociais intrínsecas à dinâmica da comunidade têm contribuído para a regulação dos recursos, garantindo, assim, a continuidade da atividade ao longo dos anos, como também, por atuarem no processo de resiliência e sustentabilidade dos sistemas socioecológicos.

Dessa forma, afirma-se que as práticas de manejo relatadas pelos pescadores entrevistados estão embasadas sobre um saber coletivo, difundido pela oralidade e transmitido de pai para filho ao longo das gerações, englobando conhecimentos sobre o ambiente, as espécies e suas formas de captura. A utilização desses saberes na atividade pesqueira local tem garantido a subsistência familiar e contribuído para a sustentabilidade dos Sistemas de Pesca.

Ações de manejo institucional também fazem parte da dinâmica pesqueira da comunidade por meio das regulamentações. Estas regulamentações visam proteger os ambientes e recursos explorados, bem como os aspectos socioculturais da comunidade. $\mathrm{Na}$ área, regulamentações específicas já citadas com a IN no 40/2005 (BRASIL, 2005) e as de âmbito nacional como a IN Interministerial $n^{\circ}$ 6/2017 (BRASIL, 2017) e a IN no 206/2008 (BRASIL, 2008) que tratam respectivamente da captura do caranguejo-uçá (Ucides cordatus) e das lagostas vermelha (Panulirus argus) e verde (Panulirus laevicauda) têm contribuído para a exploração sustentável. Entretanto, não contemplam as especificidades de todos os sistemas identificados, que também carecem de medidas regulatórias, sendo destacadas pelos entrevistados ações que regulem o tamanho mínimo de captura do marisco (Anomalocardia brasiliana) e do sururu (Mytella guyanensis).

Salienta-se que a área ainda não possui Plano de Manejo Pesqueiro e que a fiscalização das práticas pelos órgãos gestores da APA é pouco eficiente, com atuação comumente durante a reprodução do caranguejo-uçá (Ucides cordatus), época em que os exemplares capturados pelos pescadores são medidos. A atuação irregular dos órgãos gestores tem refletido negativamente na sustentabilidade pesqueira de Barra Grande devido à falta de monitoramento das capturas, sobretudo das realizadas por pescadores que não pertencem à comunidade.

Assim, ações específicas de regulamentação, monitoramento e fiscalização da atividade devem ser implementadas com a participação dos seus principais usuários, os pescadores de Barra Grande, para que garantam a continuidade da pesca na comunidade. 


\section{Considerações finais}

A relevância social, econômica e cultural da atividade pesqueira para a comunidade de Barra Grande tem contribuído para a continuidade do modo de vida alicerçado na pesca, sendo possível constatar a sustentabilidade dos modelos de exploração da pesca artesanal, os quais estão embasados no saber desses povos sobre os ambientes, os recursos e suas formas de captura.

Atributos sociais, ecológicos, tecnológicos, econômicos e de manejo identificados, a exemplo de benefícios sociais, organização de classe, seletividade das artes, aproveitamento do pescado e manejo tradicional da pesca apontam aspectos positivos da atividade que necessitam ser contemplados nas políticas de gestão dos recursos pesqueiros, pois retratam formas de explotação que têm assegurado a continuidade da atividade.

As ações de manejo tradicional praticadas no cotidiano dos pescadores são diversas e contemplam atividades que têm garantido a resiliência dos sistemas explorados. Dessa forma, entende-se que a adoção de medidas de manejo embasadas no conhecimento tradicional, bem como em estilos de vida que respeitam a limitação biológica dos recursos e protegem os ambientes fazem dos pescadores de Barra Grande-PI, agentes fundamentais de manejo pesqueiro, cuja participação em processos decisórios da pesca agrega conhecimento e valoriza a tradição pesqueira da comunidade, contribuindo, assim, para a sustentabilidade da atividade.

\section{Referências}

ALMEIDA, S. Z.; NAHUM, V. J. I. Os recursos pesqueiros marinhos e estuarinos do Maranhão: biologia, tecnologia, socioeconomia, estado de arte e manejo. Novas Edições Acadêmicas, 2015. 292p.

ALMEIDA, Z. S.; NAHUM, V. J. I.; SANTOS, N. B.; PAZ, A. C. Diagnóstico dos sistemas de produção pesqueira artesanais do litoral do Maranhão. São Luís: Editora UEMA, 2010. 125p.

BAILEY, K. Methods of social research. $4^{\mathrm{a}}$ ed. New York: The Free Press, 1994. 588p.

BAPTISTA, E. M. C; HORN FILHO, N. O. Mapa geológico da planície costeira adjacente aos recifes de arenito do litoral do estado do Piauí. Revista Geonorte, Edição Especial 4, v.10, n.1, p.105-109, 2014.

BARBETTA, P. A. Estatística aplicada às Ciências Sociais. 6 ed. Florianópolis: Editora da UFSC, 2006. 315p.

BASÍLIO, T. H.; SILVA, E. V.; FLORESI, D. B.; GOMES, M. P.; GARCEZ, D. S. Sustentabilidade das atividades pesqueiras do município de Piúma, litoral sul do Espírito Santo, Brasil. Arquivos de Ciências do Mar, n. 48, v. 1, p. 69-86, 2015. 
BRASIL. Decreto 6.040, de 07 de fevereiro de 2007. Institui a Política Nacional de Desenvolvimento Sustentável dos Povos e Comunidades Tradicionais. Brasília: Diário Oficial da União, 2007.

BRASIL. Instrução Normativa Interministerial MAPA/MMA no 6, de 16 de janeiro de 2017. Proíbe a captura, o transporte, o beneficiamento, a industrialização e a comercialização de qualquer indivíduo da espécie Ucides cordatus, conhecido popularmente como caranguejo-uçá, nos Estados do Pará, Maranhão, Piauí, Ceará, Rio Grande do Norte, Paraíba, Pernambuco, Alagoas, Sergipe e Bahia, durante a "andada". Brasília: Diário Oficial da União, 2017.

BRASIL. Instrução Normativa no 40, de 18 de outubro de 2005. Estabelece normas para 0 período de proteção à reprodução natural dos peixes (piracema), na Bacia Hidrográfica do Rio Parnaíba. Brasília: Diário Oficial da União, 2005.

BRASIL. Instrução Normativa no 206, de 14 de novembro de 2008. Proíbe nas águas sob jurisdição brasileira, o exercício da pesca das lagostas vermelha (Panulirus argus) e verde (Panulirus laevicauda), anualmente, no período de $1^{\circ}$ de dezembro a 31 de maio. Brasília: Diário Oficial da União, 2008.

BRASIL. Lei no 11.959, de 29 de junho de 2009. Dispõe sobre a Política Nacional de Desenvolvimento Sustentável da Aquicultura e da Pesca, regula as atividades pesqueiras....Brasília: Diário Oficial da União, 2009.

CAVALCANTI, A. P. B. Impactos e condições ambientais da zona costeira do Estado do Piauí. 2000. 353f. Tese (Doutorado em Geografia) - Instituto de Geociências e Ciências Exatas - UNESP, Rio Claro, 2000.

CONCEIÇÃO, R. N. L.; NASCIMENTO, M. C. Recifes artificiais instalados em Guamaré, Rio Grande do Norte: programa de apoio à pesca artesanal. Arquivos de Ciências do Mar, v. 42, n. 1, p. 106-111, 2009.

DIAS NETO, J. Gestão do uso dos recursos pesqueiros marinhos no Brasil. Brasília: IBAMA, 2010. 242p.

DUTRA, A. S.; PEREIRA, R. M. F. A. O município de Cajueiro da Praia (PI), Brasil: características naturais e a conservação de um patrimônio socioambiental. Resgate - Revista Interdisciplinar de Cultura, v.23, n.30, p. 57-68, jul./dez, 2015.

FAGUNDES NETTO, E. B.; ZALMON, I. R. Recursos pesqueiros marinhos: Estratégias para o manejo e conservação. In: I Seminário Nacional de Gestão Sustentável de Ecossistemas Aquáticos: Complexidade, interatividade e ecodesenvolvimento, 2012, Arraial do Cabo. Rio de Janeiro: Editora COPPE/UFRJ, v. 1, p. 51- 63, 2012.

FREITAS, S. T.; PAMPLIN, P. A.Z.; LEGAT, J.; FOGAÇA, F. H. S.; BARROS, R. F. M. Conhecimento tradicional das marisqueiras de Barra Grande, área de Proteção Ambiental do Delta do Rio Parnaíba, Piauí, Brasil. Ambiente e Sociedade, v. 15, n. 2, p. 91-112, 2012. 
GONÇALVES, Z. L. T.; CABRAL, M. I. A.; NEVES, T. M.; SANTOS, C. A. B.; NOGUEIRA, E. M. S. Sociedades tradicionais e conservação da natureza. Revbea, São Paulo, v. 13, n. 4, p. 79-86, 2018.

GUZZI, A. (org). Biodiversidade do Delta do Parnaíba: litoral piauiense. Parnaíba: EDUFPI, 2012. 465p.

HAIMOVICI, M. (org.). Sistemas pesqueiros marinhos e estuarinos do Brasil: caracterização e análise da sustentabilidade. Rio Grande: Ed. da FURG, 2011.104p.

HAIMOVICI, M.; ANDRIGUETTO FILHO M.; SUNYE, P. S. A pesca marinha e estuarina no Brasil: estudos de caso multidisciplinares. Rio Grande: Editora da FURG, 2014.191p.

MARRUL FILHO, S. Crise e sustentabilidade no uso dos recursos pesqueiros. Brasília: Ibama, 2003. 147p.

PADILHA, R. A.; HENKES, J. A. A utilização de recifes artificiais marinhos como ferramenta de recuperação da fauna marinha. Revista Gestão e Sustentabilidade Ambiental, v. 1, n. 1, p. 41-73. 2012.

PEREIRA, B. E.; DIEGUES, A. C. Conhecimento de populações tradicionais como possibilidade de conservação da natureza: uma reflexão sobre a perspectiva da etnoconservação. Desenvolvimento e Meio Ambiente, v. 22, p 37-50, 2010.

PEZZUTI, J. C. B.; BARBOZA, R. S. L.; NUNES, I.; MIORANDO, P.; FERNANDES, L. Etnoecologia e conservação de quelônios amazônicos: um estudo de caso. In: Alves, R. R. N.; SOUTO, W. M. S.; MOURÃO, J. S. (orgs.). A etnozoologia no Brasil: importância, status atual e perspectivas. Recife, PE: NUPEEA. p. 447-469, 2010.

SANTOS, L. C. M.; GASALLA, M. A.; DAHDOUH-GUEBAS, F.; BITENCOURT, M. D. Socio-ecological assessment for environmental planning in coastal fishery areas: A case study in Brazilian mangroves. Ocean and Coastal Management, v. 138, p. 60-69, 2017.

SANTOS, M. P. N; SEIXAS, S.; AGGIO, R. B. M.; HANAZAKI, N.; COSTA, M.; SCHIAVETTI, A.; DIAS, J. A.; AZEITEIRO, U. M. A Pesca enquanto atividade humana: pesca artesanal e sustentabilidade. Revista de Gestão Costeira Integrada/Journal of Integrated Coastal Zone Management, v. 12, n. 4, p. 405-427, 2012.

SILVANO, R. A. M.; BEGOSSI, A. Fishermen's local ecological knowledge on Southeastern Brazilian coastal fishes: contributions to research, conservation, and management. Neotropical Ichthyology, v. 10, n.1, p. 133-147, 2012.

STORI, F. T.; NORDI, N.; ABESSA, D. M. S. Mecanismos socioecológicos e práticas tradicionais de pesca na comunidade caiçara da llha Diana (Santos, Brasil) e suas transformações. Revista de Gestão Costeira Integrada/Journal of Integrated Coastal Zone Management, v. 12, n. 4, p. 521-533, 2012. 